\title{
The role of abortion in the last stage of fertility decline in Vietnam
}

\section{Bussarawan Teerawichitchainan}

Sajeda Amin

Population Council

Follow this and additional works at: https://knowledgecommons.popcouncil.org/departments_sbsr-pgy

Part of the Demography, Population, and Ecology Commons, Family, Life Course, and Society Commons, Gender and Sexuality Commons, International Public Health Commons, Obstetrics and Gynecology Commons, and the Women's Health Commons How does access to this work benefit you? Let us know!

\section{Recommended Citation}

Teerawichitchainan, Bussarawan and Sajeda Amin. 2009. "The role of abortion in the last stage of fertility decline in Vietnam," Poverty, Gender, and Youth Working Paper no. 15. New York: Population Council. Version of record: https://doi.org/10.1363/ipsrh.36.080.10 


\section{POVERTY, GENDER, AND YOUTH}

\section{The Role of Abortion in the Last Stage of Fertility Decline}

in Vietnam

Bussarawan Teerawichitchainan and Sajeda Amin 


\section{(2) Population Council}

One Dag Hammarskjold Plaza

New York, New York 10017 USA

www.popcouncil.org

pubinfo@popcouncil.org

For information on Poverty, Gender, and Youth working papers, see www.popcouncil.org/publications/wp/index.html

This material may not be reproduced without written permission from the authors.

ISSN: $1554-8538$

(C) 2009 The Population Council, Inc. 


\title{
The Role of Abortion in the Last Stage of Fertility Decline in Vietnam
}

\author{
Bussarawan Teerawichitchainan
}

Sajeda Amin

Bussarawan Teerawichitchainan is Assistant Professor of Sociology, School of Social Sciences, Singapore Management University, bteerawichit@smu.edu.sg. Sajeda Amin is Senior Associate, Poverty, Gender, and Youth Program, Population Council, samin@popcouncil.org. 


\begin{abstract}
Vietnam's rapid fertility decline from 5.7 births per woman in 1979 to 2.1 in 2005 can be explained by very high rates of contraceptive use and induced abortion. Despite the overall decline, fertility rates vary considerably across the country's 54 ethnic groups. While the majority Vietnamese (i.e., Kinh) and a few other ethnic minority groups have already completed the transition to replacement-level fertility, this is not the case for a substantial fraction of Vietnam's disproportionately poor ethnic minority populations. The last stage of fertility decline in Vietnam, therefore, has much to do with addressing the needs of ethnic minorities. To explore the prospects for further fertility decline through use of abortion among high-fertility minority populations, this study analyzes unique data from the Vietnam National Health Survey to examine ethnic differentials in prevalence and determinants of abortion and contraception, using a new classification system for ethnicity. We find that use of abortion is high in Vietnam but not as high as previously reported. Abortion is more common among older and better-educated women with more children and among married women from the more privileged ethnic minority groups. Our findings also suggest that abortion rates are higher among married women who practice traditional methods of contraception. Abortion is more closely correlated with volition rather than disempowerment. Providing improved abortion services by itself is unlikely to reduce fertility among high-fertility minority groups. Service provision needs to be offered along with policies and other steps that improve family planning programs and promote women's education and later-age childbearing.
\end{abstract}


Vietnam's total fertility rate dropped from 5.7 births per woman in 1979 to 3.8 in 1989 and 2.1 in 2005. Despite the overall rapid decline, fertility rates vary considerably across the country's 54 ethnic groups. The majority Vietnamese (i.e., Kinh), who account for 84 percent of Vietnam's total population of 86 million, have completed the transition to replacement-level fertility. Like the Kinh, some ethnic minority groups such as Chinese, Tay, Thai, Muong, and Nung have also achieved low levels of fertility. This is not the case for ethnic minorities in the Northern Uplands and Central Highlands, who tend to be poor and account for about 75 percent of Vietnam's 14-million ethnic minority population. For example, according to the 1999 census, the Dao and the Hmong- the two most populous ethnic minority groups in the Northern Uplands-had total fertility rates of 3.6 and 7.1 respectively. While recent estimates suggest declining fertility among these two groups, many minority groups still have fertility rates well above replacement and report relatively high prevalence of unmet need for family planning (UNFPA 2007; VCPFC and Macro ORC 2003). Completing the last stage of fertility decline in Vietnam, therefore, will require addressing the reproductive health and family planning needs of ethnic minorities.

Vietnam's rapid fertility decline is associated with high rates of both contraceptive use and induced abortion (Haughton 1997). Induced abortion, primarily provided by the government free of charge or with minimal fees, is available upon request to married couples at most levels of public health facilities. Official statistics show that in the mid-1990s the total abortion rate in Vietnam averaged 2.5 procedures per woman (Goodkind 1994). With such a high rate, abortion is thought to have been adopted as an alternative to contraception, particularly among the Kinh and among low-fertility minority groups (Do et al. 1993). To explore the role of abortion in further fertility decline among high-fertility minority populations in Vietnam, this study analyzes unique data from the 2001 Vietnam National Health Survey (VNHS) to examine ethnic differentials in prevalence and determinants of abortion and contraception, using a new classification system for ethnicity based on poverty indicators, geographic location, and degree of assimilation of ethnic groups. Given that ethnic minority groups in Vietnam are disproportionately poor, we assess whether ethnic differentials in abortion and contraception can be explained by their socioeconomic characteristics and the accessibility and quality of family planning services in their local communities. Further, contributing to the debate on relationships between contraceptive use and abortion, this study assesses whether Vietnamese women's use of certain contraceptive methods correlates with their decision to seek abortion and the extent to which the correlations vary by ethnic groups.

\section{BACKGROUND}

Vietnam's family planning policy has played an important role in the rapid decline in fertility over the last three decades. A population policy was first formulated in 1963 by the socialist government of North Vietnam. The regime planned to lower the annual population growth rate from 3.5 to 2 percent by advising couples to limit their family size to 2-3 children with 5-6 years of birth spacing ( $\mathrm{Vu}$ 1992). Because of the scarcity of resources and other disruptions caused by the Vietnam War (1965-75), the success of this initial population policy was limited; yet, it did increase availability of contraception and abortion services in northern 
Vietnam. After the reunification of North and South Vietnam in 1975, the regime expanded family planning services to the South, where fertility rates had been higher than in the North and pronatalist policies were instituted before the 1970s. In 1988, the government implemented an antinatalist population policy, which called for one or two children per family and three-to-fiveyear birth spacing, along with free provision of contraceptives and abortion services, cash incentives for sterilization, and penalties for violations (Goodkind 1995). Although the government was strongly motivated to pursue population policies and followed many of the same measures adopted by the Chinese government, for a number of reasons the policy measures were less draconian, articulated as a one-or-two-child policy rather than a one-child policy.

Another key institutional force in Vietnam's fertility decline was the establishment of the National Council of Population and Family Planning (NCPFP) in 1984. By the late 1980s, the NCPFP had established provincial offices, commune-level branches, and networks of villagelevel family planning promoters. Rather than using coercion as was the case with China's family planning campaigns, Vietnam's family planning program appeared to be subtly manipulative. According to Gammeltoft's ethnographic study in northern Vietnam (1999), family planning was not entirely voluntary. Local family planning promoters used personal relationships and incessantly emphasized economic and normative disincentives related to excessive childbearing to make people feel obligated to have no more than two children.

Until fairly recently, Vietnam's family planning strategy tended to favor the IUD over other methods of contraception (Knodel et al. 1995). Evidence indicates that teams of health workers who visited villages were expected to meet targets of IUD insertions. The strategy, borrowed from other socialist states, was driven by a lack of resources to provide inexpensive supply-based alternative contraceptive methods and by a desire to maintain centralized control over the medical establishments that provided family planning services (Goodkind 1994). According to the 2002 Vietnam Demographic and Health Survey, virtually all Vietnamese women of reproductive age knew of at least one method of contraception, and the IUD was the most widely known method. Likewise, the IUD was by far the most commonly used method among currently married women: 65 percent reported that they had ever used the method, whereas 38 percent reported currently using it. Despite increasing prevalence of other methods such as the pill and condom, the IUD, which was first imported from Czechoslovakia and China in the 1960s, has remained the most extensively used contraceptive method in Vietnam.

Abortion services were promoted vigorously in Vietnam's early family planning campaigns alongside the promotion of the IUD. ${ }^{1}$ Since 1989, the regime has been committed to providing abortion free of charge to eligible persons who register to practice family planning. All possible grounds for abortion are permitted as long as the procedure is conducted by health professionals. A majority of abortions are provided at public health facilities, which are available in cities, prosperous villages, and even remote rural areas served by mobile teams. Fees for abortion services vary according to the administrative level of health clinics and the economic status of provinces ${ }^{2}$ (Do 2008). In poor, rural, and mountainous areas abortion services are available free of charge. Private abortion providers have purportedly become increasingly common after Vietnam's economic reforms in the late 1980s. It is not possible to ascertain what proportion of abortion services is offered by private providers. According to Goodkind (1994), the estimate was approximately 15 percent during the mid-1990s. 
Vietnam has one of the world's highest abortion rates (Henshaw et al. 1999). While abortion has been available since the 1960s, it was not common until the early 1980s. At first, its prevalence began to increase slowly and then rose rapidly from 1988 with the introduction of the one-or-two-child policy. The number of abortions reported by the Ministry of Health has risen substantially from 160,000 in 1979 to 810,000 in 1987 and 1.34 million in 1992. Abortion rates peaked in the early 1990s at nearly 100 per 1,000 married women of reproductive age. Recent official estimates suggested a sharp decline in abortion since the mid-1990s; yet, nationally representative surveys indicated small increases in incidence. ${ }^{3}$ No firm conclusions can therefore be drawn with regard to recent abortion trends in Vietnam (Sedgh et al. 2007). Government estimates in the mid-1990s suggest that menstrual regulation accounted for approximately 45-60 percent of all pregnancy terminations. Goodkind (1994) argues that high prevalence of abortion in Vietnam is the result of antinatalist population policies interacting with a lack of contraceptive alternatives. The one-or-two-child policy calls for penalties for third and higher-parity births and for violations of the three-to-five-year spacing rule. Although evidence suggests that the regime has been less strict about enforcing the rules among populations in remote areas, who tend to belong to ethnic minority groups, fines have been imposed in certain areas (Gammeltoft 1999). Some women may have been deterred by the penalties and by fear of complicated abortion procedures. Therefore, they chose to undergo menstrual regulation as a precautionary measure even when they were uncertain about their pregnancy (Trinh et al. 1998).

Although Vietnam has already achieved high contraceptive prevalence among most of its population of reproductive age, recent studies question use-effectiveness, quality, and accessibility of family planning services (Do and Koenig 2007; Nguyen and Dang 2002). While the IUD is dominant among modern methods, the use of traditional methods remains widespread. In the context of inadequate availability and inefficient use of contraceptives, researchers argue that Vietnamese women might use abortion to achieve their desired family size. While the government of Vietnam no longer adopts abortion as a preferred family planning method, the procedure remains heavily subsidized by the state, and many publicized family planning campaigns still list abortion as a method of birth control after the IUD, condom, and pill. Whether Vietnam's high-fertility ethnic groups will achieve replacement-level fertility in the coming years remains to be seen. Understanding the role of abortion in explaining ethnic differentials in fertility outcomes can help evaluate the prospects for further fertility decline and identify reproductive health needs among ethnic minorities in Vietnam.

\section{DATA}

Conducted in 2001 by the Ministry of Health and the General Statistics Office, the Vietnam National Health Survey (VNHS) is a population-based, nationally representative sample data set that provides a unique resource for analyzing ethnic differentials in reproductive behaviors. Data are derived from a three-stage, stratified, cluster random probability sample of 36,000 households containing nearly 160,000 individuals from 1,200 communes nationwide. The VNHS interviewed women ages 12-49 with a husband or with children under age 5 in the sample households about their reproductive history and behavior. The survey contains detailed information regarding a respondent's birth history in the five years preceding the survey, current 
methods of contraception, unwanted pregnancy, and history of abortion and/or menstrual regulation in the five years preceding the survey. In this study, we restrict our analyses to 27,097 currently married women ages 15-49. Owing to a sampling design that produced unequal probabilities of cluster selection, we adjust for clustering and stratification effects.

The VNHS permits not only a comparison of reproductive behavior between the Kinh and ethnic minorities but also a comparison within Vietnam's 53 minority groups. Despite ample evidence of differences in socioeconomic and cultural characteristics within ethnic minority groups (Baulch et al. 2004), most empirical studies tend to lump all ethnic minorities into one category, ${ }^{4}$ thus failing to distinguish diversity within the minority populations. Such a crude analytic approach is in part due to a survey sampling strategy that yields an inadequate number of observations of specific minority groups. Unlike other surveys, data from the VNHS allow us to construct a new classification system for ethnicity that captures various nuances of ethnic minority populations.

\section{DEPENDENT VARIABLES}

We examine two outcome variables. First, current method of contraception is measured as a categorical variable indicating whether at the time of the survey a respondent or her spouse used any modern method, traditional method, or no method to space or prevent a birth. Modern methods include the IUD, pill, contraceptive injection, implants, condom, diaphragm/gel/foaming tablet, and sterilization. Traditional methods include periodic abstinence and withdrawal. Approximately 59 percent of currently married women ages 15-49 reported using modern methods at the time of survey, whereas 20 percent used traditional methods and 21 percent did not use any contraception. The second outcome variable is incidence of abortion, incorporated as a dummy variable indicating whether a respondent had an abortion or menstrual regulation within the five years prior to the survey. Because the VNHS also asked each respondent how many times she had abortions and menstrual regulations during 1997-2001, we are able to calculate total abortion rates. ${ }^{5}$ Approximately 12 percent of married women in the sample reported having at least one abortion or menstrual regulation during the period examined. The total abortion rate was 0.67 abortions per woman.

The VNHS offers high-quality information on deliberate pregnancy termination, thus allowing us to explore use of abortion in detail. Past studies on abortion in Vietnam rely primarily on official data compiled from service providers. The accuracy of these statistics is questionable (Goodkind 1994; Trinh et al. 1998). Those data are funneled upward to the Ministry of Health in a hierarchical fashion. Standard forms are filled out by the provincial departments of health based on information from public providers and assembled by district health departments. Not only is the collection of such data not uniform across districts and provinces, but certain districts or provinces might over-report the number of abortions they performed, especially during the early 1990s, in order to impress the central administration or to receive additional resources. Although international experience suggests that the collection of data on abortion in household surveys can be problematic, several measures were implemented in the VNHS to ensure the quality of abortion data collection (Bales 2003). Only women who were married were asked about their abortion history. Because termination of unwanted pregnancies is legal for 
married women in Vietnam and stigma against abortion among this segment of the population is minimal, greater accuracy of reporting is likely to be achieved. Further, during data entry, data coders were instructed to cross-check information on unwanted pregnancy, abortion, and cost of abortion to identify inconsistencies and possible errors. Moreover, a post-enumeration survey was also carried out, permitting an assessment of the quality and validity of VNHS data. Findings suggest only a small discrepancy ( 7 percent) in abortion reporting between the main survey and post-enumeration results (Bales 2003: 70-74).

\section{Predictor VARIABles}

Ethnicity is a key independent variable in this study. We recognize the varying levels of socioeconomic assimilation and economic development among ethnic minorities in different regions of Vietnam. Our ethnic classification scheme attempts to address such differences. We categorize the sample into five clusters comprising 1) Kinh-Chinese; 2) Tay, Thai, Muong, Nung (TTMN); 3) ethnic minorities (EM) in the South; 4) minorities in the Northern Uplands; and 5)

minorities in the Central Highlands. ${ }^{6}$ In this study, the Kinh-Chinese account for 85 percent of the sample and the TTMN comprise 8 percent. Although the TTMN reside predominantly in Vietnam's Northern Uplands, they tend to be more economically assimilated to the Kinh than to other minority groups from the same region. Ethnic groups in the South account for about 1.5 percent of the sample. Minorities in the Northern Uplands, including the Dao and Hmong, account for 3.5 percent of the VNHS sample. The minority populations in the Central Highlands are among the poorest in Vietnam and account for 2.5 percent of the study sample.

As evident in Table 1, there are considerable variations in total fertility rates and agespecific patterns of fertility across the five ethnic clusters presented here (see also Amin and Teerawichitchainan 2009). All minority groups, particularly those in the Northern Uplands and Central Highlands, have higher fertility levels than the Kinh-Chinese. Ethnic fertility differences are negligible in the youngest age group, but differentials emerge for the 20-24 age group and are constant across every age thereafter. The fertility differentials are driven by large differences in the highest-fertility age group beginning with the 20-24 age group. The age-specific patterns of the TTMN, who are closest to the Kinh-Chinese in the overall levels, are particularly distinctive in having high early-age fertility that drops rapidly after age 30.

In addition to ethnicity, other predictor variables incorporated in this study are woman's age, number of living children, educational attainment, location of residence, household wealth status, and frequency of family planning program implementation. Table 2 presents the distribution of each independent variable by respondent's ethnicity. Proportions of married women under age 25 in the sample are higher among minorities in the Northern Uplands (25 percent) and the Central Highlands (29 percent) compared to the three other groups. We expect high prevalence of contraception, particularly modern methods, and high incidence of abortion among older women of reproductive age who have already reached their government-mandated or desired family size. Another demographic variable is the number of living children, measured as a categorical variable indicating whether a respondent had no child or whether she had one, two, or three or more living children at the time of survey. Among Kinh-Chinese, 35 percent of women had three or more births. This proportion was considerably greater among minority 
women, especially those in the South, Northern Uplands, and Central Highlands. We hypothesize that married women who have reached a family size of two or higher would be more inclined to practice modern contraception or to seek pregnancy termination to avoid additional births.

Further, women's educational attainment is incorporated as a categorical variable. Ethnic differentials in educational attainment are salient. The Kinh-Chinese were generally better educated than minority women. Minorities in the Northern Uplands were among the least educated: about two-thirds were illiterate, and most of those with some education had fewer than 6 years of schooling. We expect better-educated women to demonstrate higher prevalence rates of contraceptive practice, especially effective use of modern methods, and in turn to be less likely to resort to abortion for birth control.

Two household characteristics are included as proxies for geographic and economic accessibility of modern contraception and abortion. First, location of residence is measured as a categorical variable indicating whether a respondent resided in 1) urban areas (towns and cities); 2) rural areas in the lowlands and low mountainous terrain; or 3) rural areas in high mountainous terrain. A much larger proportion of the Kinh-Chinese lived in urban areas compared to their minority counterparts. We hypothesize that residents of urban, lowland, and low mountainous areas have greater access to reproductive health services than those in more remote highland areas. A second proxy for accessibility is household economic status. In the VNHS, households were stratified into five per capita household expenditure quintiles of equal size defining relative living standards in the population (Bales 2003). In this study, households in the lowest quintile are classified as poor, while the rest are categorized as less poor. While only 13 percent of the Kinh-Chinese were poor, ethnic minorities, particularly those in the Northern Uplands and Central Highlands, lived disproportionately in poverty. We expect women from less-poor households to have greater access to modern methods of contraception and to abortion services. According to Bongaarts and Westoff (2000), increased access to family planning services will generally lead to rising prevalence of modern contraception and, in turn, reduced incidence of unwanted pregnancies and abortion.

Closely related to program accessibility, quality of family planning programs may have significant implications for women's contraceptive use and their decision to seek abortion. This study is restricted by the VNHS' limited information on family planning service quality. Therefore, as a rough proxy for service quality, we incorporate a measure of how often family planning programs were implemented by commune health centers ${ }^{7}$ ( $\mathrm{CHC}$ ) during the 12 months preceding the survey. Because activities implemented were not specified in the VNHS, they may include routine distribution of pills or condoms, consultations, outreach activities, or mobile clinics. The variable is measured as a categorical variable indicating whether a respondent lived in a community in which family planning programs are implemented less than once per quarter, quarterly, monthly, or more than once a month. Overall, a majority of women in the sample lived in communities in which family planning services were provided regularly. This was particularly true for the Kinh-Chinese and minorities in the South. Higher frequency of program implementation suggest greater family planning accessibility and, to a certain extent, higher service quality. This, in turn, is expected to increase effective use of modern contraception and reduce the risk of unwanted pregnancy and abortion. 


\section{DESCRIPTIVE RESULTS}

Figure 1 describes ethnic patterns in current methods of contraception among married women of reproductive age. One of the most striking findings is the high prevalence of women in all ethnic groups who reported currently using modern contraceptive methods. While substantially higher proportions of TTMN women reported use of modern contraception (70 percent) than other ethnic groups, the prevalence rates of modern contraceptive use fluctuated narrowly among the other four groups. In an analysis not shown here, we found that the IUD was by far the most common modern contraceptive used by all ethnic groups. This was particularly the case for minorities in the Northern Uplands, where nearly 80 percent of those who were using modern contraception chose the IUD. Other common methods were the pill, female sterilization, and the condom.

In addition to high prevalence of modern contraceptive use, Figure 1 also shows the relatively widespread practice of traditional contraceptive methods among the Kinh-Chinese. Over one-fifth of Kinh-Chinese women used traditional methods to prevent births. Further, results indicate that non-use of contraception was substantial among high-fertility minority groups such as those in the Northern Uplands (38 percent) and Central Highlands (36 percent). For ethnic groups that have already reached replacement-level fertility, such as the Kinh-Chinese and TTMN, contraceptive non-use was reported among approximately one-fifth of married women of reproductive age.

Table 3 shows ethnic patterns in total abortion rates during the five years preceding the survey. On average a married woman in Vietnam had 0.67 abortions during her reproductive years. ${ }^{8}$ This estimate is comparable to the total abortion rate of 0.60 based on the 2002 Vietnam Demographic and Health Survey (VCPFC and Macro ORC 2003) but significantly lower than the rate of 2.50 abortions derived from service providers' data (Goodkind 1994). In addition, results indicate significant variations in total abortion rates across ethnic groups. The incidence of abortion was highest (0.80 abortions) among TTMN women, who also reported the highest prevalence of modern contraceptive use. Total abortion rates were lower for the Kinh-Chinese (0.68 abortions) and for minorities in the South and Northern Uplands (0.49 abortions). Incidence of abortion was lowest among minority women in the Central Highlands, who averaged 0.30 abortions during their reproductive years. Further, Table 2 provides age-specific abortion rates during 1997-2001 for each ethnic cluster. Across all groups, abortion was very rare among married women under age 20 and peaked among women in their late 20s and 30s before declining thereafter. This pattern was particularly salient for low-fertility groups such as the Kinh-Chinese and TTMN.

\section{Multivariate Results}

Findings from descriptive analyses shown in Figure 1 and Table 3 confirm prior studies indicating that low fertility in Vietnam was likely achieved by high prevalence of both contraceptive use and induced abortion. This was most apparent among ethnic groups that had reached replacement-level fertility, such as the TTMN and the Kinh-Chinese. To further examine individual, household, and community characteristics associated with contraceptive use and abortion, we analyze determinants of use of current methods of contraception and induced 
abortion in a multivariate framework. In Table 4, we estimate a maximum-likelihood multinomial logistic regression model for assessing the net effect of women's characteristics. The determinants of use of contraceptive methods are assessed by estimating the odds of women adopting modern or traditional methods relative to the omitted category, non-use of contraception.

Results suggest that ethnicity had independent effects on married women's choice of current contraceptive methods. Compared to the Kinh-Chinese, TTMN women had higher odds of adopting modern methods; yet they were less likely to use traditional methods relative to nonuse of contraception. Meanwhile, minority women in the Northern Uplands and Central Highlands were less likely than the Kinh-Chinese to use either modern or traditional contraceptive methods to prevent births. Assuming other characteristics to be equal, only minorities in the South demonstrated no significant difference from the majority group in terms of current methods of contraception.

Women's age is one of the most important determinants of current contraceptive methods. Women at every age group older than 20 were several times more likely than those under age 20 to practice either modern or traditional contraception. The odds of adopting modern methods peaked among women in their late 30s, whereas women in their early 40s were most likely to practice traditional methods relative to non-use of contraception. In addition to age, women's education had significant and noteworthy influences on their contraceptive use. Not only did education increase the likelihood of adopting modern contraception, but women with at least a few years of schooling also were more likely to use traditional methods than were those who were illiterate.

Further, findings indicate the importance of women's family size and household characteristics in determining their current contraceptive methods. Women who had already given birth were more likely to use either modern or traditional methods relative to non-use than were those without any children. This was particularly true for women with two children. However, having three or more children did not have any independent effects on women's contraceptive use. As proxies for family planning accessibility, neither poor household status nor rural location of residence (either lowland or highland) appeared to deter women's adoption of modern contraception. Rural women were more likely than their urban counterparts to practice both modern and traditional methods relative to non-use of contraception. While living in poor households reduced the likelihood that women would adopt traditional contraception, it did not show any net effects on women's modern contraceptive use. Likewise, frequency of family planning program implementation in women's local communities did not appear to significantly influence their choice of current methods of contraception.

Married women's age, education, location of residence, and, to a certain extent, family size and household economic status are found to be important determinants of their use of current contraceptive methods. Net of the effects of these characteristics, the lowest-fertility groups such as the Kinh-Chinese appeared to achieve their fertility goals by greater use of traditional methods. The analysis presented in Table 5 further investigates whether these covariates influenced use of induced abortion. The determinants of abortion are assessed using binary logistic regression models. The analysis consists of four additive models. The first model presents abortion as a function of ethnicity; Model 2 incorporates respondent's age; Model 3 
adds education and the number of living children; and Model 4 incorporates proxies for family planning accessibility and quality, including location of residence, household wealth, and frequency of commune health center implementation of family planning programs. The exponentiated coefficients are presented as the ratio of the odds of having an abortion for each category, relative to the comparable odds of the reference category for each covariate.

Results suggest significant differences in abortion incidence between the Kinh-Chinese and the TTMN and ethnic minorities in the Central Highlands. Assuming other characteristics to be equal, TTMN women were more likely than the Kinh-Chinese to undergo induced abortion. Meanwhile, women in the Central Highlands had lower odds of abortion compared to the majority Vietnamese. The coefficients for these two groups changed modestly after the introduction of individual, household, and community characteristics. We found no significant differences between the Kinh-Chinese and minorities from the South. While coefficients in Models 1 and 2 suggest that minorities from the Northern Uplands have less likelihood of abortion than the Kinh-Chinese, the net effects disappear in Model 3 for these minority groups, suggesting the differences in abortion between these groups and the Kinh-Chinese can be explained by women's background characteristics such as education and family size.

Similar to its effect on women's choice of current contraceptive method, age is one of the most prominent predictors of abortion. Women in their prime reproductive years from the mid20 s to the early 40 s were several times more likely than those under age 20 to seek abortion. The independent effects of age were modified modestly when other characteristics were controlled. In addition to women's age, their educational attainment increased the likelihood of seeking abortion to prevent births. Married women with 6 years of schooling or higher had significantly greater odds of experiencing abortion, whereas no significant differences in abortion incidence were found between illiterate women and those with only primary education. Results suggest modest effects of women's family size on induced abortion. Relative to childless women, having one or two children increased women's likelihood of abortion, while having three or more children did not.

While household location and economic status had significant influences on women's choice of contraception, they had no significant effects on abortion when these factors were taken into consideration in Model 4. This is perhaps explained by Vietnam's population policies, which have heavily subsidized abortion and menstrual regulation and made them widely available for married women in various levels of public health facilities. Interestingly, we also find that the quality of family planning programs, as measured by how frequently the programs were implemented at the community level, could influence women's odds of seeking pregnancy termination. Results in Model 4 indicate that when the programs were implemented at least once every three months, women's likelihood of abortion was reduced by nearly 30 percent.

The descriptive and multivariate analyses reveal two noteworthy patterns of reproductive behavior among married women that explain ethnic differentials in fertility outcomes. The first pattern was observed among low-fertility populations such as the Kinh-Chinese, the TTMN, and, to a certain extent, Southern minorities. This segment of the Vietnamese population had high rates of modern contraceptive use and abortion, as well as widespread practice of traditional methods of contraception. The second pattern reflects the experience of high-fertility groups such as minorities in the Northern Uplands and Central Highlands. Although their prevalence of 
modern contraception was comparable to that of the Kinh-Chinese, these groups were less likely to practice traditional methods or resort to abortion. The rates of contraceptive non-use were relatively high for these minority groups, who live mainly in remote areas. In addition to significant ethnic variations in reproductive behavior, our analyses also indicate that women's background characteristics such as education significantly determined their choice of current contraceptive methods and their decision to seek abortion. While education increased the odds of married women adopting modern contraception, results also indicate that better-educated women were more likely than those with no or only primary education to use traditional methods as well as abortion. Contrary to our expectations, living in remote areas or coming from poor households did not deter married women from using modern contraception or seeking abortion. Yet, the increased frequency of community-level implementation of family planning programs, especially in resource-poor remote areas, could decrease the incidence of abortion among married women.

\section{Potential Linkages Between ConTraCePtion AND ABORTION}

Recent evidence suggests potential roles of increased contraceptive prevalence and effectiveness in reducing abortion rates (Bongaarts and Westoff 2000; Marston and Cleland 2003). We are restricted in our ability to draw causal relationships between contraception and abortion because the VNHS asked respondents only about their current method of contraception, not about the methods used before each pregnancy termination. Even so, insights can be gained from exploring correlations between current contraceptive methods and induced abortion, especially in the context of Vietnam where prevalence rates of contraception and abortion are among the world's highest.

Figure 2 depicts the percentage distribution of married women who had one or more induced abortions in the five years preceding the survey for each current method of contraception used. Current users of modern methods reported lower abortion incidence than traditional method users. However, considerable variations in abortion incidence were seen among users of different modern methods, suggesting low use-effectiveness for certain methods. For example, among current IUD users, who accounted for more than one-third of all married women in the sample, 9 percent experienced at least one induced abortion during 1997-2001. Meanwhile, proportions of induced abortions were higher for users of less-common modern methods such as the pill (18 percent) and the condom (20 percent). Unlike modern method users, women using traditional methods, who accounted for about one-fifth of the sample, had consistently high rates of abortion: approximately 17 percent for women who used rhythm to prevent births and 19 percent for those who practiced withdrawal. This correlation points to possible linkages between a combined use of traditional methods and abortion to prevents birth among married women in Vietnam.

\section{DISCUSSION}

Our findings indicate that prevalence of abortion is high in Vietnam but not as high as previously reported on the basis of data from service providers. According to analysis of the Vietnam National Health Survey, a married woman had on average 0.67 abortions during her reproductive years. Our analysis suggests that abortion was more common among older and 
better-educated women with higher-parity births, and among married women from the Kinh majority group and more socioeconomically privileged ethnic minority groups such as the Tay, Thai, Muong, Nung, and ethnic Chinese. Further, our evidence shows that abortion incidence was higher among married women who practiced traditional methods of contraception. Abortion was therefore more closely correlated with volition rather than with disempowerment. Socioeconomic factors associated with privilege and status can explain ethnic differences in abortion among minority women in the Northern Uplands. For this group, once socioeconomic factors were controlled (Table 5, Model 3), no abortion differentials were seen. Among other ethnic minorities, abortion remains consistently high for TTMN and low for Central Highland minorities, and prevalence is unaltered by the inclusion of socioeconomic controls. With regard to the implications of our findings for further fertility decline in Vietnam, our results suggest that service provision strategies should be adapted to meet the particular needs of different highfertility ethnic groups. While for the Northern Uplands the appropriate strategy might be to increase access to education and provide higher-quality abortion services, for the Central Highlands, where rates of abortion are the lowest, access to abortion is unlikely to reduce the region's relatively high levels of fertility. It is possible that religious factors deter minority groups in the Central Highlands from practicing abortion. Many minorities in the Central Highlands were exposed to Catholicism and the influence of French missionaries in the nineteenth century (Hickey 1964: 14-15). Reproductive health services for these ethnic groups may need to be offered in conjunction with policies and other steps that improve family planning programs and promote women's education and later-age childbearing.

Given limited choices of modern contraceptive methods in Vietnam, our analyses show that members of more privileged ethnic groups have achieved replacement-level fertility and compliance with the state's one-or-two-child policy by combining practice of traditional contraceptive methods with induced abortion. According to anecdotal evidence, many women who use traditional contraceptive methods such as periodic abstinence and withdrawal have considered abortion as a backup (Do 2008; Johansson et al. 1996). Women justify their reproductive choice by referring to the belief that traditional and natural family planning methods pose fewer risks to their health and ability to work than modern contraceptive methods such as the IUD. Because other methods of contraception such as the pill and condom have become more widely available in recent years, continuing high rates of abortion in Vietnam are attributable to failures to provide ancillary services, especially counseling on the effective use of contraception. These high abortion rates also reflect the Vietnamese population's inadequate awareness of reproductive health, including proper knowledge of the use of contraception.

\section{NoTES}

1 Two types of pregnancy termination are available. Menstrual regulation (hut thai in Vietnamese) is performed by a suction procedure within five weeks of pregnancy, whereas abortion (nao thai) refers to all other pregnancy-termination procedures performed after five weeks and up to 12 weeks or longer. In this study, unless indicated, abortion is used as a general term referring to both menstrual regulation and abortion. 
2 The fees range from 40,000 VND (US\$2.35) for first-trimester abortion to 1.5 million VND (US\$88) for second-trimester abortion. Family planning subscribers who experience a method failure have access to abortion services free of charge.

3 A 2004 study by Ganatra and colleagues quoted a senior official in Vietnam's Ministry of Health as saying that approximately 700,000-800,000 abortions are performed each year in Vietnam by public providers.

4 The only exception is ethnic Chinese, who account for about one percent of the total population. Because ethnic Chinese usually enjoy high socioeconomic status and reside in urban areas, particularly in Ho Chi Minh City, researchers tend to combine them with the majority Kinh. We follow this practice here.

5 This measure is analogous to a total fertility rate. It indicates the average number of abortions a woman would be expected to have during her reproductive lifetime, given current age-specific abortion rates.

6 Ethnic minorities in the South are Khmer, Cham, Xtieng, and Cho-ro. Minorities in the Northern Uplands are Hmong, Dao, Ngai, San Chay, San Diu, Giay, Kho-mu, Khang, Xinh-mun, Ha Nhi, Lao, La Chi, La Ha, Phu La, La Hu, Lu, Lo Lo, Mang, Pa Then, Co Lao, Cong, Bo Y, Si La, and Pu Peo. Minorities in the Central Highlands are Gia-rai, Ede, Ba na, Xo-dang, Co ho, Mnong, Gie Trieng, Ma, Chu ru, Brau, Ro mam, Hre, Raglai, Bru Van Kieu, Tho, Cotu, Co, Ta-oi, Chut, and O-du.

7 Commune health centers are the main grassroots public health facilities available throughout Vietnam. CHCs provide basic primary care and implement various preventive care programs, including family planning services.

8 While the official abortion statistics were likely inflated, we are mindful that women might also underreport abortion in surveys. Nonetheless, given how abortion data were collected and processed in the VNHS (as described earlier), we expect that underreporting will not be a major problem for our study.

\section{REFERENCES}

Amin, Sajeda and Bussarawan Teerawichitchainan. 2009. "Ethnic Fertility Differentials in Vietnam." Paper presented at the Annual Meeting of the Population Association of America, April 30-May 2.

Bales, Sarah. 2003. Technical Documentation For The Vietnam National Health Survey 2001-2. Hanoi, Vietnam: Ministry of Health and Statistics Sweden International Consulting Office.

Baulch, Bob, Truong Thi Kim Chuyen, Dominique Haughton, and Jonathan Haughton. 2004. "Ethnic Minority Development in Vietnam: A Socioeconomic Development 
Perspective," pp. 273-310 in Economic Growth, Poverty, and Household Welfare in Vietnam, edited by Paul Glewwe, Nisha Agrawal, and David Dollar. Washington, DC: The World Bank.

Bongaarts, John and Charles F. Westoff. 2000. "The Potential Role of Contraception in Reducing Abortion." Studies in Family Planning 31(3): 193-202.

Do Trong Hieu, John Stoeckel, and Nguyen Van Tien. 1993. "Pregnancy Termination and Contraceptive Failure in Vietnam.” Asia-Pacific Population Journal 8(4): 3-18.

Do Mai and Michael Koenig. 2007. "Effect of Family Planning Services on Modern Contraceptive Method Continuation in Vietnam." Journal of Biosocial Science 39: 201220.

Do Thi Hong Nga. 2008. “More to Demand: Abortion in Vietnam.” Women in Action 1: 6-10.

Gammeltoft, Tine. 1999. Women's Bodies, Women's Worries: Health and Family Planning in a Vietnamese Rural Community. Richmond, England: Curzon Press.

Ganatra, Bela, Marc Bygdeman, Phan Bich Thuy, Nguyen Duc Vinh, and Vu Manh Loi. 2004. "From research to reality: The challenges of introducing medical abortion into service delivery in Vietnam." Reproductive Health Matters 12 (24 Supplement): 105-113.

Goodkind, Daniel. 1994. "Abortion in Vietnam: Measurements, Puzzles, and Concerns.” Studies in Family Planning 25(6): 342-352.

- 1995. "Vietnam's One-or-Two-Child Policy in Action." Population and Development Review 21(1): 85-111.

Haughton, Jonathan. 1997. “Falling Fertility in Vietnam.” Population Studies 51: 203-211.

Henshaw, Stanley K., Susheela Singh, and Taylor Haas. 1999. "The Incidence of Abortion Worldwide.” International Family Planning Perspectives 25(Supplement): S30-S38.

Hickey, Gerald C. 1964. The Major Ethnic Groups of the South Vietnamese Highlands. Santa Monica: RAND, April 1964, RM-4041-ARPA.

Johansson, Annika, Le Thi Nham Tuyet, Nguyen the Lap, and Kajsa Sundstrom. 1996. "Abortion in Context: Women's Experience in Two Villages in Thai Binh Province, Vietnam." International Family Planning Perspectives 22(3): 103-107.

Knodel, John, Phan Thuc Anh, Truong Viet Dung, and Dao Xuan Vinh. 1995. "Why is oral contraceptive use in Vietnam so low?" International Family Planning Perspectives 21(1): 11-18. 
Marston, Cicely and John Cleland. 2003. "Relationships between Contraception and Abortion: A Review of the Evidence." International Family Planning Perspectives 29(1): 6-13.

Nguyen Minh Thang and Dang Nguyen Anh. 2002. "Accessibility and Use of Contraceptives in Vietnam.” International Family Planning Perspectives 28(4): 214-219.

Sedgh, Gilda, Stanley K. Henshaw, Susheela Singh, Akinrinola Bankole, and Joanna Drescher. 2007. "Legal Abortion Worldwide: Incidence and Recent Trends." International Family Planning Perspectives 33(3): 106-116.

Trinh Huu Vach, Amie Bishop, Vuong Thi Hoa, Luong Xuan Hien, Tran Dinh Chien, and Nguyen I. Tuong. 1998. "The Potential Impact of Introducing Pregnancy Testing into Menstrual Regulation Services in Vietnam.” International Family Planning Perspectives 24(4): 165-169.

United Nations Population Fund (UNFPA). 2007. Knowledge And Behavior Of Ethnic Minorities On Reproductive Health. Hanoi.

Vietnam Committee for Population, Family and Children (VCPFC) and ORC Macro. 2003. Vietnam Demographic and Health Survey 2002. Calverton, MD: Committee for Population, Family and Children and ORC Macro.

Vu Quy Nhan. 1992. "Population Policies and Development in Vietnam." Pp. 40-54 In The Challenges of Vietnam's Reconstruction, edited by Neil Jamieson, Nguyen Manh Hung, and A. Terry Rambo. Fairfax, VA: The Indochina Institute of George Mason University. 
Table 1. Age-specific fertility rates and total fertility rates by ethnicity, 19972001

\begin{tabular}{|c|c|c|c|c|c|c|}
\hline Age group & $\begin{array}{c}\text { All } \\
\text { women }\end{array}$ & $\begin{array}{c}\text { Kinh- } \\
\text { Chinese }\end{array}$ & TTMN & EM-South & $\begin{array}{c}\text { EM- } \\
\text { Northern } \\
\text { Uplands }\end{array}$ & $\begin{array}{c}\text { EM- } \\
\text { Central } \\
\text { Highlands }\end{array}$ \\
\hline $15-19$ & 0.03 & 0.02 & 0.06 & 0.01 & 0.10 & 0.08 \\
\hline $20-24$ & 0.34 & 0.32 & 0.50 & 0.28 & 0.57 & 0.52 \\
\hline $25-29$ & 0.55 & 0.54 & 0.58 & 0.58 & 0.70 & 0.61 \\
\hline $30-34$ & 0.37 & 0.36 & 0.29 & 0.39 & 0.46 & 0.58 \\
\hline $35-39$ & 0.21 & 0.20 & 0.11 & 0.27 & 0.33 & 0.51 \\
\hline $40-44$ & 0.08 & 0.07 & 0.04 & 0.15 & 0.21 & 0.33 \\
\hline $45-49$ & 0.03 & 0.02 & 0.03 & 0.05 & 0.26 & 0.18 \\
\hline TFR & $\mathbf{1 . 5 9}$ & $\mathbf{1 . 5 4}$ & $\mathbf{1 . 6 2}$ & $\mathbf{1 . 7 3}$ & $\mathbf{2 . 6 3}$ & $\mathbf{2 . 8 0}$ \\
\hline
\end{tabular}

Source: VNHS 2001 
Table 2. Descriptive Statistics, Demographic and socioeconomic characteristics of currently married women ages $15-49$.

\begin{tabular}{|c|c|c|c|c|c|}
\hline \multirow[t]{2}{*}{ Women's characteristics } & $\begin{array}{l}\text { Kinh- } \\
\text { Chinese }\end{array}$ & TTMN & EM- South & $\begin{array}{c}\text { EM- } \\
\text { Northern } \\
\text { Uplands }\end{array}$ & $\begin{array}{l}\text { EM-Central } \\
\text { Highlands }\end{array}$ \\
\hline & $(\mathrm{N}=22,969)$ & $(\mathrm{N}=2,076)$ & $(\mathrm{N}=418)$ & $(\mathrm{N}=946)$ & $(\mathrm{N}=688)$ \\
\hline \multicolumn{6}{|l|}{ Age } \\
\hline Total & $100 \%$ & $100 \%$ & $100 \%$ & $100 \%$ & $100 \%$ \\
\hline $15-19$ & 1 & 4 & 2 & 7 & 6 \\
\hline $20-24$ & 12 & 16 & 12 & 18 & 23 \\
\hline $25-29$ & 20 & 20 & 21 & 21 & 20 \\
\hline $30-34$ & 20 & 20 & 20 & 18 & 17 \\
\hline $35-39$ & 20 & 19 & 18 & 18 & 13 \\
\hline $40-44$ & 16 & 14 & 15 & 11 & 13 \\
\hline $45-49$ & 11 & 8 & 11 & 6 & 9 \\
\hline \multicolumn{6}{|l|}{ Number of Living Children } \\
\hline Total & $100 \%$ & $100 \%$ & $100 \%$ & $100 \%$ & $100 \%$ \\
\hline None & 6 & 7 & 8 & 10 & 9 \\
\hline One & 22 & 18 & 16 & 14 & 14 \\
\hline Two & 37 & 34 & 26 & 23 & 19 \\
\hline Three and over & 35 & 40 & 51 & 53 & 58 \\
\hline \multicolumn{6}{|l|}{ Educational attainment } \\
\hline Total & $100 \%$ & $100 \%$ & $100 \%$ & $100 \%$ & $100 \%$ \\
\hline Illiterate & 4 & 16 & 38 & 66 & 56 \\
\hline 5 years or below & 44 & 49 & 55 & 29 & 38 \\
\hline 6-9 years & 33 & 24 & 5 & 4 & 4 \\
\hline $10+$ years & 19 & 11 & 2 & 1 & 2 \\
\hline \multicolumn{6}{|l|}{ Location of residence } \\
\hline Total & $100 \%$ & $100 \%$ & $100 \%$ & $100 \%$ & $100 \%$ \\
\hline Urban & 25 & 7 & 13 & 3 & 8 \\
\hline Rural-Lowland and low mountainous & 69 & 29 & 85 & 14 & 13 \\
\hline Rural-High mountainous & 5 & 63 & 1 & 83 & 80 \\
\hline \multicolumn{6}{|l|}{ Household wealth status } \\
\hline Total & $100 \%$ & $100 \%$ & $100 \%$ & $100 \%$ & $100 \%$ \\
\hline Poor & 13 & 51 & 34 & 78 & 91 \\
\hline Less poor & 87 & 49 & 66 & 22 & 9 \\
\hline \multicolumn{6}{|l|}{$\begin{array}{l}\text { Frequency of CHC implementation of } \\
\text { family planning programs }\end{array}$} \\
\hline Total & $100 \%$ & $100 \%$ & $100 \%$ & $100 \%$ & $100 \%$ \\
\hline Less than once per quarter & 7 & 24 & 3 & 25 & 20 \\
\hline Quarterly & 3 & 12 & 5 & 16 & 14 \\
\hline Monthly & 22 & 16 & 24 & 16 & 23 \\
\hline More than once a month & 68 & 47 & 68 & 43 & 42 \\
\hline Source: VNHS 2001 & & & & & \\
\hline
\end{tabular}


Figure 1. Distribution of current methods of contraception among married women ages $15-49$ by ethnicity

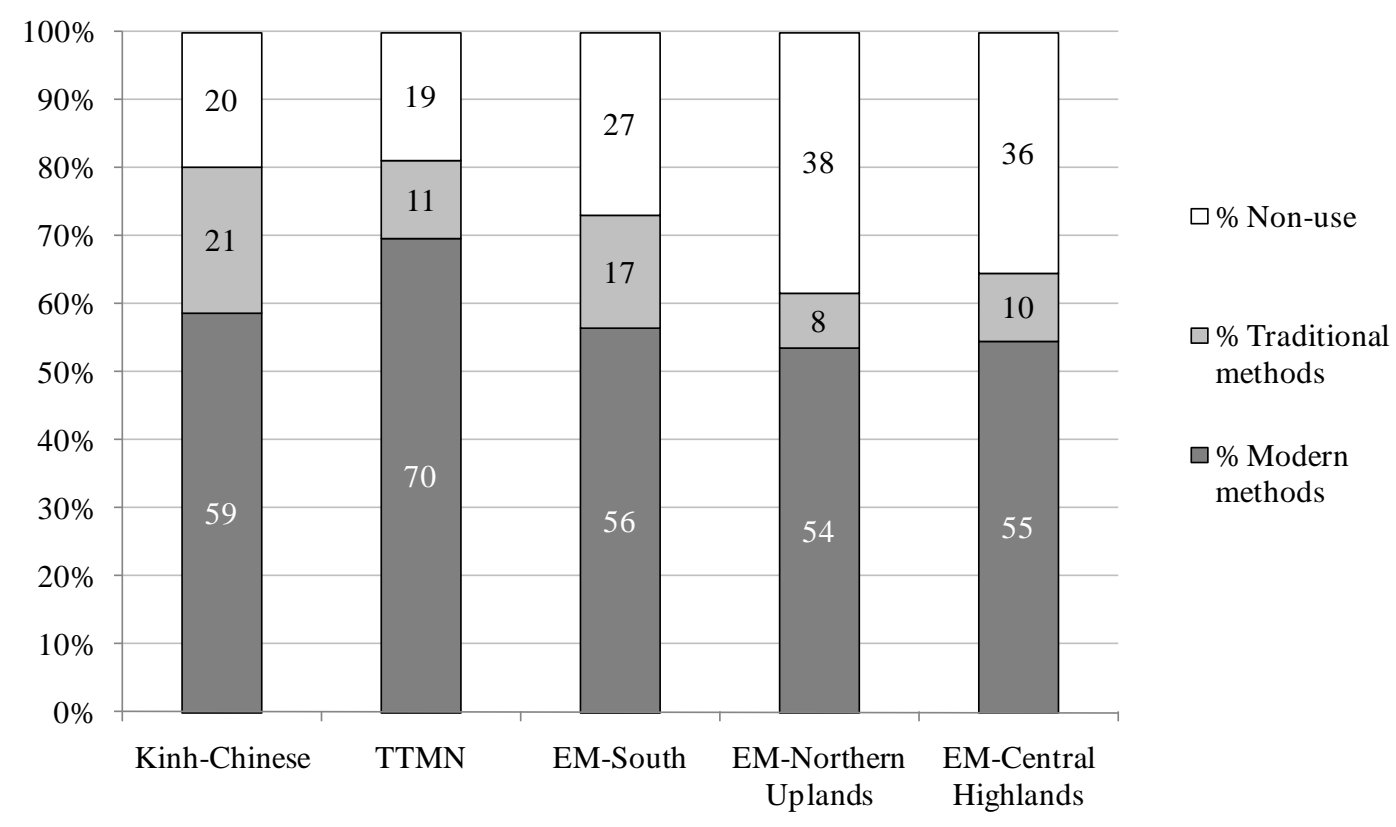

Source: VNHS 2001

Table 3. Incidence of abortion during 1997-2001 by ethnicity among currently married women ages $15-49$

\begin{tabular}{|c|c|c|c|c|c|c|}
\hline & & & & & & \\
\hline Age groups & All women & $\begin{array}{c}\text { Kinh- } \\
\text { Chinese }\end{array}$ & TTMN & EM-South & $\begin{array}{c}\text { EM- } \\
\text { Northern } \\
\text { Uplands }\end{array}$ & $\begin{array}{c}\text { EM-Central } \\
\text { Highlands }\end{array}$ \\
\hline $15-19$ & 0.01 & 0.01 & 0.00 & 0.00 & 0.01 & 0.00 \\
\hline $20-24$ & 0.08 & 0.08 & 0.09 & 0.00 & 0.03 & 0.02 \\
\hline $25-29$ & 0.14 & 0.14 & 0.20 & 0.09 & 0.13 & 0.05 \\
\hline $30-34$ & 0.15 & 0.16 & 0.18 & 0.15 & 0.08 & 0.03 \\
\hline $35-39$ & 0.14 & 0.14 & 0.13 & 0.10 & 0.13 & 0.02 \\
\hline $40-44$ & 0.11 & 0.11 & 0.13 & 0.12 & 0.07 & 0.18 \\
\hline $45-49$ & 0.05 & 0.05 & 0.07 & 0.04 & 0.04 & 0.00 \\
\hline Total abortion rate & 0.67 & 0.68 & 0.80 & 0.49 & 0.49 & 0.30 \\
\hline Source: VNHS 2001 & & & & & & \\
\hline
\end{tabular}


Table 4. Maximum-likelihood multinomial logistic regression, Determinants of the use of current methods of contraception among currently married women ages 15-49.

\begin{tabular}{|c|c|c|c|c|}
\hline \multirow{3}{*}{ Women's characteristics } & \multicolumn{4}{|c|}{ Current methods of contraception $^{\mathrm{a}}$} \\
\hline & \multicolumn{2}{|c|}{ Modern method } & \multicolumn{2}{|c|}{ Traditional method } \\
\hline & $\begin{array}{r}\text { Odds } \\
\text { ratio }\end{array}$ & $\begin{array}{r}\text { Std. } \\
\text { err }\end{array}$ & $\begin{array}{l}\text { Odds } \\
\text { ratio }\end{array}$ & $\begin{aligned} \text { Std. } \\
\text { err }\end{aligned}$ \\
\hline \multicolumn{5}{|l|}{ Ethnicity (Kinh-Chinese=ref) } \\
\hline TTMN & $1.54 * * *$ & 0.12 & $0.78 *$ & 0.08 \\
\hline EM-South & 0.81 & 0.10 & 0.76 & 0.12 \\
\hline EM-Northern Uplands & $0.74 * *$ & 0.08 & $0.38 * * *$ & 0.06 \\
\hline EM-Central Highlands & $0.68 * * *$ & 0.07 & $0.44 * * *$ & 0.07 \\
\hline \multicolumn{5}{|l|}{ Age (Under 20=ref) } \\
\hline $20-24$ & $3.53 * * *$ & 0.44 & $1.92 * *$ & 0.36 \\
\hline $25-29$ & $8.02 * * *$ & 0.98 & $4.98 * * *$ & 0.92 \\
\hline $30-34$ & $14.52 * * *$ & 1.80 & $9.78 * * *$ & 1.81 \\
\hline $35-39$ & $24.76 * * *$ & 3.14 & $19.89 * * *$ & 3.70 \\
\hline $40-44$ & $19.78 * * *$ & 2.51 & $20.54 * * *$ & 3.82 \\
\hline $45-49$ & $5.53 * * *$ & 0.69 & $8.25 * * *$ & 1.53 \\
\hline \multicolumn{5}{|l|}{ Educational attainment (Illiterate $=$ ref) } \\
\hline 5 years or below & $1.41 * * *$ & 0.09 & $1.83 * * *$ & 0.16 \\
\hline $6-9$ years & $1.61 * * *$ & 0.11 & $1.97 * * *$ & 0.19 \\
\hline $10+$ years & $1.27 * *$ & 0.10 & $1.61 * * *$ & 0.16 \\
\hline \multicolumn{5}{|l|}{ Number of Living Children (None=ref) } \\
\hline One & $1.30 * * *$ & 0.07 & $1.82 * * *$ & 0.11 \\
\hline Two & $2.55 * * *$ & 0.11 & $2.88 * * *$ & 0.15 \\
\hline Three and over & 0.92 & 0.07 & 0.91 & 0.09 \\
\hline \multicolumn{5}{|l|}{ Location of residence (Urban=ref) } \\
\hline Rural-Lowland and low mountainous & $1.23 * * *$ & 0.05 & $1.12 *$ & 0.05 \\
\hline Rural-High mountainous & $1.20 *$ & 0.08 & $1.20 *$ & 0.10 \\
\hline Poor household (Less poor=ref) & 1.07 & 0.05 & $0.84 * *$ & 0.05 \\
\hline \multicolumn{5}{|c|}{$\begin{array}{l}\text { Frequency of CHC implementation of family } \\
\text { planning programs (<Quarterly=ref) }\end{array}$} \\
\hline Quarterly & 1.09 & 0.10 & 0.91 & 0.10 \\
\hline Monthly & 1.11 & 0.07 & 0.98 & 0.08 \\
\hline More than once a month & 1.13 & 0.07 & 0.96 & 0.07 \\
\hline
\end{tabular}

Total number $=27,097$

$*$ significant at $\mathrm{p}<0.05, * *$ significant at $\mathrm{p}<0.01, * * *$ significant at $\mathrm{p}<0.001$

${ }^{a}$ The omitted category for the equation is non-use of contraception

Source: VNHS 2001 
Table 5. Binary logistic regression, Determinants of the use of induced abortion among currently married women ages 15-49.

\begin{tabular}{|c|c|c|c|c|c|c|c|c|}
\hline \multirow[b]{2}{*}{ Women's characteristics } & \multicolumn{2}{|l|}{ Model 1} & \multicolumn{2}{|l|}{ Model 2} & \multicolumn{2}{|c|}{ Model 3} & \multicolumn{2}{|l|}{ Model 4} \\
\hline & $\begin{array}{l}\text { Odds } \\
\text { ratio }\end{array}$ & $\begin{array}{l}\text { Std. } \\
\text { err. }\end{array}$ & $\begin{array}{l}\text { Odds } \\
\text { ratio }\end{array}$ & $\begin{array}{l}\text { Std. } \\
\text { err. }\end{array}$ & $\begin{array}{l}\text { Odds } \\
\text { ratio }\end{array}$ & $\begin{array}{l}\text { Std. } \\
\text { err. }\end{array}$ & $\begin{array}{l}\text { Odds } \\
\text { ratio }\end{array}$ & $\begin{array}{l}\text { Std. } \\
\text { err. }\end{array}$ \\
\hline \multicolumn{9}{|l|}{ Ethnicity (Kinh-Chinese=ref) } \\
\hline TTMN & $1.22 * *$ & 0.08 & $1.23 * *$ & 0.08 & $1.32 * * *$ & 0.09 & $1.24 * *$ & 0.10 \\
\hline EM-South & 0.79 & 0.13 & 0.79 & 0.14 & 1.03 & 0.18 & 1.05 & 0.18 \\
\hline EM-Northern Uplands & $0.61 * * *$ & 0.08 & $0.64 * * *$ & 0.08 & 0.86 & 0.12 & 0.79 & 0.12 \\
\hline EM-Central Highlands & $0.15 * * *$ & 0.04 & $0.16 * * *$ & 0.04 & $0.22 * * *$ & 0.06 & $0.20 * * *$ & 0.06 \\
\hline \multicolumn{9}{|l|}{ Age (Under 20=ref) } \\
\hline $20-24$ & & & $9.83 * * *$ & 4.99 & $8.94 * * *$ & 4.54 & $9.06 * * *$ & 4.61 \\
\hline $25-29$ & & & $19.84 * * *$ & 10.00 & $16.09 * * *$ & 8.12 & $16.45 * * *$ & 8.30 \\
\hline $30-34$ & & & $21.20 * * *$ & 10.68 & $16.73 * * *$ & 8.44 & $17.13 * * *$ & 8.64 \\
\hline $35-39$ & & & $18.28 * * *$ & 9.21 & $15.02 * * *$ & 7.58 & $15.39 * * *$ & 7.77 \\
\hline $40-44$ & & & $13.64 * * *$ & 6.88 & $11.80 * * *$ & 5.96 & $12.09 * * *$ & 6.11 \\
\hline $45-49$ & & & $6.01 * * *$ & 3.05 & $5.63 * *$ & 2.87 & $5.80 * *$ & 2.96 \\
\hline \multicolumn{9}{|l|}{ Educational attainment (Illiterate $=$ ref) } \\
\hline $0-5$ years & & & & & 1.01 & 0.10 & 1.05 & 0.10 \\
\hline $6-9$ years & & & & & $1.36 * *$ & 0.13 & $1.43 * * *$ & 0.14 \\
\hline $10+$ years & & & & & $1.63 * * *$ & 0.16 & $1.67 * * *$ & 0.18 \\
\hline \multicolumn{9}{|l|}{ Number of Living Children (None $=$ ref) } \\
\hline One & & & & & $1.17 *$ & 0.07 & $1.18 *$ & 0.08 \\
\hline Two & & & & & $1.43 * * *$ & 0.07 & $1.44 * * *$ & 0.07 \\
\hline Three and over & & & & & 0.85 & 0.12 & 0.84 & 0.12 \\
\hline \multicolumn{9}{|l|}{ Location of residence $($ Urban $=$ ref $)$} \\
\hline Rural-Lowland and low mountainous & & & & & & & 0.93 & 0.04 \\
\hline Rural-High mountainous & & & & & & & 0.95 & 0.08 \\
\hline Poor household (Less poor=ref) & & & & & & & 1.09 & 0.07 \\
\hline \multicolumn{9}{|c|}{$\begin{array}{l}\text { Frequency of } \mathrm{CHC} \text { implementation of } \\
\text { family planning programs (<Quarterly=ref) }\end{array}$} \\
\hline Quarterly & & & & & & & $0.77 *$ & 0.08 \\
\hline Monthly & & & & & & & $0.77 * * *$ & 0.06 \\
\hline More than once a month & & & & & & & $0.72 * * *$ & 0.05 \\
\hline df & 4 & & 10 & & 16 & & 22 & \\
\hline Log likelihood & -9483.82 & & -9257.14 & & -9158.1 & & -9134.02 & \\
\hline Number & 27097 & & 27097 & & 27097 & & 27097 & \\
\hline
\end{tabular}

* significant at $\mathrm{p}<0.05, * *$ significant at $\mathrm{p}<0.01, * * *$ significant at $\mathrm{p}<0.001$

Source: VNHS 2001 
Figure 2. Potential linkages between contraception and abortion, Currently married Vietnamese women ages 15-49.

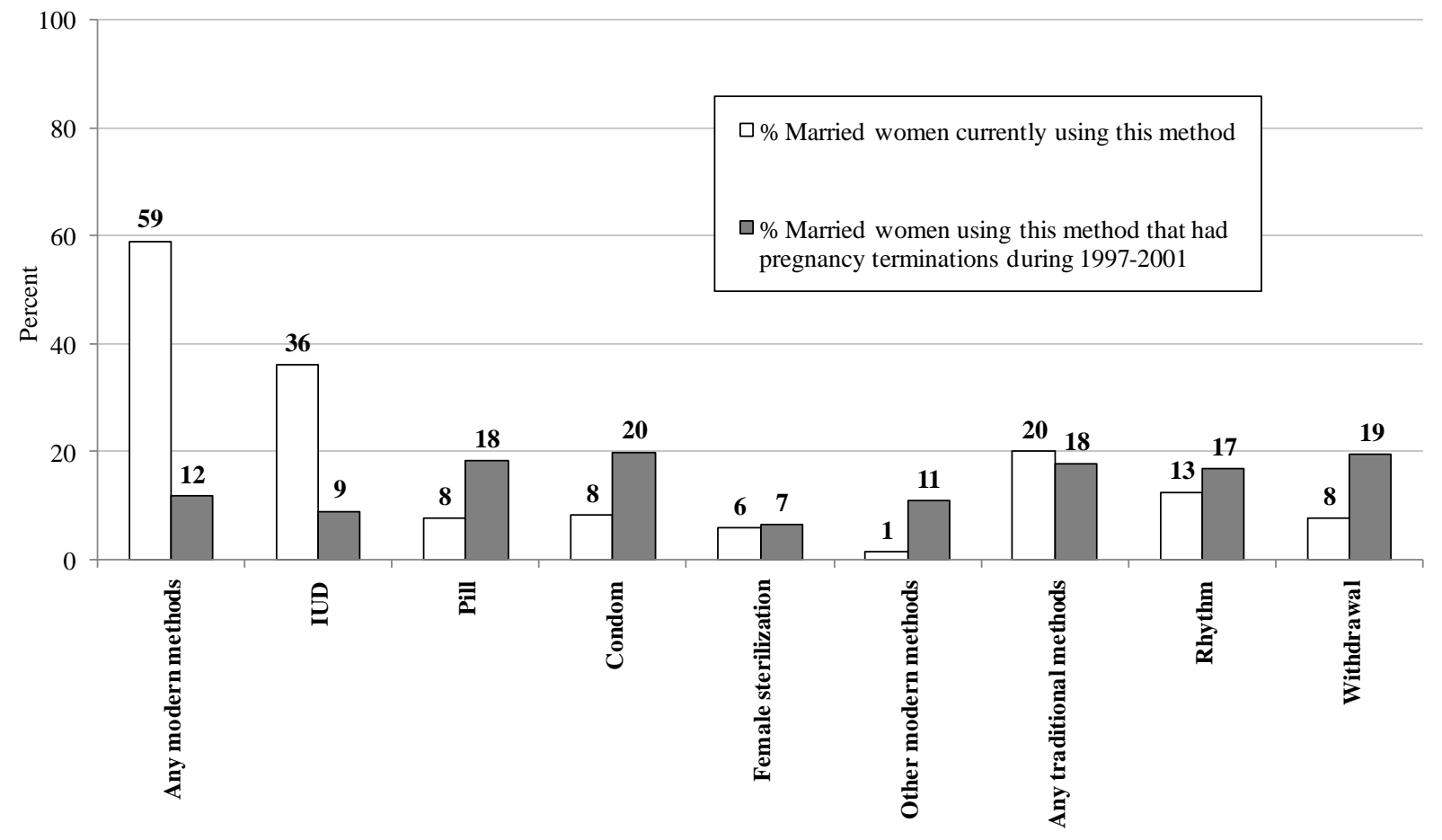

Source: VNHS 2001 


\section{Poverty, Gender, and Youth Working Papers}

If still in print, single copies of up to three working papers from 1989 through 2003 are available free of charge.

Beginning with the 2004 issues, working papers are no longer available in print format. Instead they are distributed electronically. As each new paper is completed, subscribers are notified by e-mail and a link to the paper is provided.

To subscribe to the Poverty, Gender, and Youth working paper e-mail notification list, or to obtain back issues from 1989 to 2003, please send your request to pgywp@ popcouncil.org.

PDFs of recent issues are available at www.popcouncil.org/publications/wp/index.html

2009

15 Bussarawan Teerawichitchainan and Sajeda Amin. "The role of abortion in the last stage of fertility decline in Vietnam."

14 Cynthia B. Lloyd and Paul C. Hewett, "Educational inequalities in the midst of persistent poverty: Diversity across Africa in educational outcomes."

13 Wendy Baldwin and Judith Diers, "Demographic data for development in sub-Saharan Africa."

2008

12 Sajeda Amin and Lopita Huq, "Marriage considerations in sending girls to school in Bangladesh: Some qualitative evidence."

11 S. Chandrasekhar and Abhiroop Mukhopadhyay, "Multiple dimensions of urban well-being: Evidence from India"

10 Sajeda Amin and Luciana Suran, "Terms of marriage and time-use patterns of young wives: Evidence from rural Bangladesh."
9 John Bongaarts, Thomas Buettner, Gerhard Heilig, and François Pelletier, "Has the HIV epidemic peaked?"

8 Barbara S. Mensch, Paul C. Hewett, Richard Gregory, and Stephane Helleringer, "Sexual behavior and STI/HIV status among adolescents in rural Malawi: An evaluation of the effect of interview mode on reporting."

7 John Bongaarts, "Fertility transitions in developing countries: Progress or stagnation?"

2007

6 Cynthia B. Lloyd, "The role of schools in promoting sexual and reproductive health among adolescents in developing countries."

5 Ann Biddlecom, Richard Gregory, Cynthia B. Lloyd, and Barbara S. Mensch, "Premarital sex and schooling transitions in four subSaharan African countries."

4 Sajeda Amin, John B. Casterline, and Laura Spess, "Poverty and fertility: Evidence and agenda." 
3 Bussarawan Teerawichitchainan and James F. Phillips, "Ethnic differentials in parental health seeking for childhood illness in Vietnam."

2 Zachary Zimmer, Kim Korinek, John Knodel, and Napaporn Chayovan, "Support by migrants to their elderly parents in rural Cambodia and

Thailand: A comparative study."

1 Sharon Ghuman and Cynthia B. Lloyd, "Teacher absence as a factor in gender inequalities in access to primary schooling in rural Pakistan." 